Document downloaded from:

http://hdl.handle.net/10251/93307

This paper must be cited as:

Elshalakany, AB.; Ali, S.; A. Amigó Mata; Eessaa, AK.; Mohan, P.; Osman, T.; Amigó, V. (2017). Microstructure and Mechanical Properties of Ti-Mo-Zr-Cr Biomedical Alloys by Powder Metallurgy. Journal of Materials Engineering and Performance. 26(3):1262-1271. doi:10.1007/s11665-017-2531-z

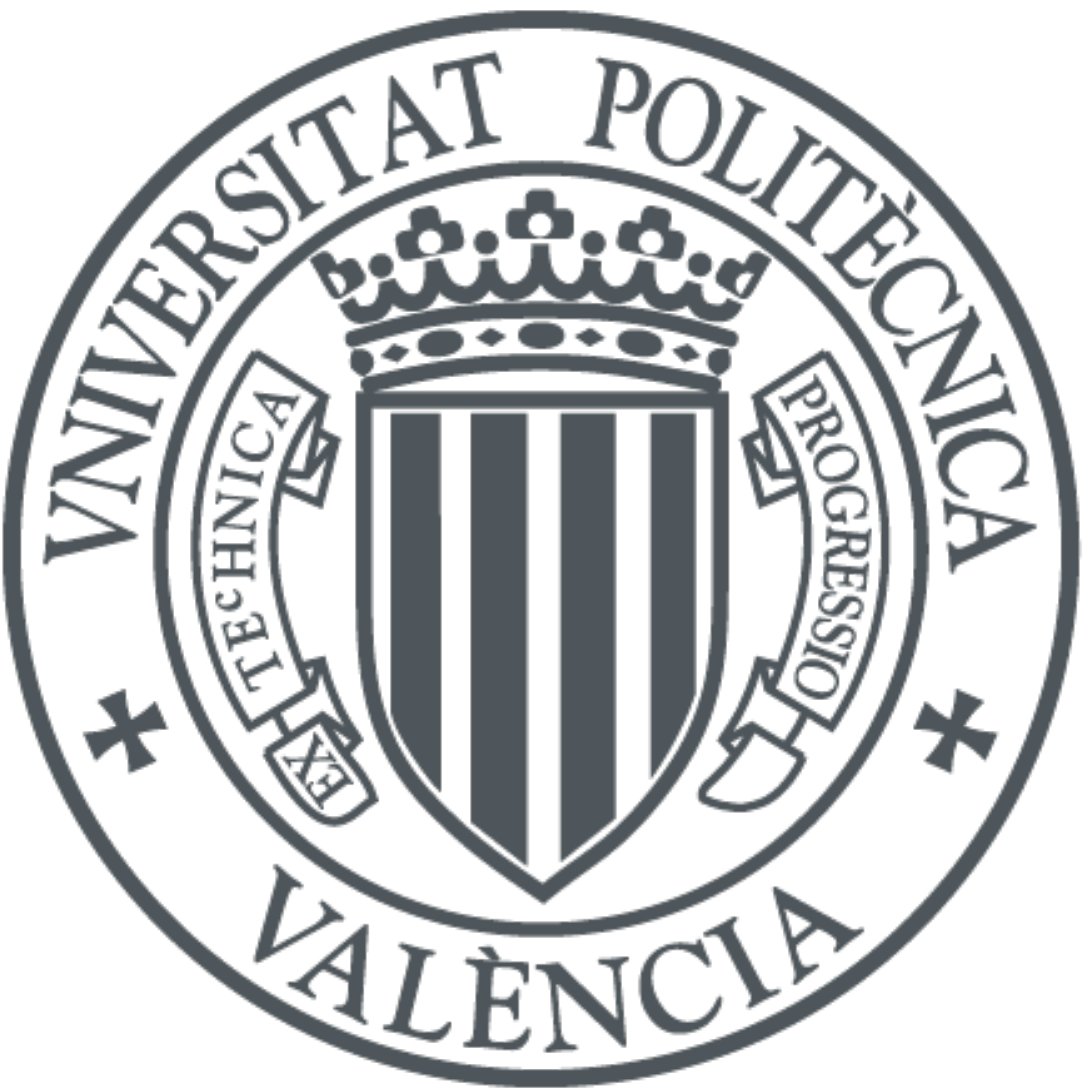

The final publication is available at

http://doi.org/10.1007/s11665-017-2531-z

Copyright Springer-Verlag

Additional Information 


\title{
Microstructure and Mechanical Properties of Ti-Mo-Zr-Cr Biomedical Alloys by Powder Metallurgy
}

\author{
Abou Bakr Elshalakany ${ }^{1,2}$, Shady Ali', A. Amigó Mata ${ }^{1}$, Ashraf K. Eessaa ${ }^{4}$, P. Mohan ${ }^{1}$, T. A. Osman ${ }^{3}$, \\ and V. Amigó Borrás ${ }^{1}$
}

${ }^{1}$ Instituto de Tecnología de Materiales. Universitat Politècnica de València, Spain

abahel@doctor.upv.es,pramo@doctor.upv.es,anamma@posgrado.upv.es; vamigo@mcm.upv.es

${ }^{2}$ Production Engineering and Printing Technology Department, Akhbar El Yom Academy, Egypt

${ }^{3}$ Mechanical Design and Production Engineering Department, Cairo University, Giza, Egypt

${ }^{4}$ Electronics Research Institute, Giza, Egypt.

\begin{abstract}
Titanium and its alloys have been widely used as biometals due to their excellent biocompatibility, corrosion resistance and moderate mechanical properties. $\mathrm{Ti}-15 \mathrm{Mo}-6 \mathrm{Zr}$ based alloys and a series of $\mathrm{Ti}-$ $15 \mathrm{Mo}-6 \mathrm{Zr}-\mathrm{xCr}(\mathrm{x}=1,2,3,4$ wt. \%) alloys were designed and fabricated by powder metallurgy for the first time to develop novel biomedical materials. The microstructure, internal porosity and mechanical properties of the sintered $\mathrm{Ti}-15 \mathrm{Mo}-6 \mathrm{Zr}$ and $\mathrm{Ti}-15 \mathrm{Mo}-6 \mathrm{Zr}-\mathrm{xCr}$ alloys were investigated using scanning electronic microscopy (SEM) and bending and compression tests. The experimental results indicated that the microstructure and mechanical properties of these alloys changed as different $\mathrm{Cr}$ levels were added. The addition of small $\mathrm{Cr}$ levels further increased the $\beta$-phase stability, improving the properties of the $\mathrm{Ti}-$ $15 \mathrm{Mo}-6 \mathrm{Zr}-\mathrm{xCr}$ alloy. However, all of the alloys had good ductility, and the $\mathrm{Ti}-15 \mathrm{Mo}-6 \mathrm{Zr}-2 \mathrm{Cr}$ alloy had lower bending and compression moduli ( 31 and $23 \mathrm{GPa}$, respectively) than the Ti-15Mo-6Zr-based alloys (40 and $36 \mathrm{GPa}$, respectively). Moreover, the $\mathrm{Ti}-15 \mathrm{Mo}-6 \mathrm{Zr}-2 \mathrm{Cr}$ alloys exhibited higher bending and compression strength/modulus ratios, which were as large as 48.4 and 52.2, respectively; these were higher than those of the Ti-15Mo-6Zr-based alloy (41.3 and 33.6, respectively). In the search for a better implant material, $\beta$ phase Ti-15Mo- $6 \mathrm{Zr}-2 \mathrm{Cr}$, with its low modulus, ductile properties, and reasonably high strength, is a promising candidate.
\end{abstract}

Keywords: Titanium alloys, Microstructure, Powder metallurgy, Implant material, Mechanical properties.

\section{INTRODUCTION}

The field of biomaterials has become a vital area because these materials can enhance the quality and longevity of human life. Also, the science and technology associated with this field contribute to a multimillion dollar business [1]. The main reasons for using Ti alloys in aerospace, chemical and medical applications are their high strength with reasonable ductility and high strength-to-weight ratio (ratio of the tensile strength to density); compared with stainless steels and $\mathrm{Co}-\mathrm{Cr}$ alloys metallic implant materials, titanium alloys are expected to be widely used for implant materials in the orthopedic and dental fields [2]. Among the metallic biomaterials, such as stainless steels and $\mathrm{Co}-\mathrm{Cr}$ alloys, titanium and its alloys exhibit the most suitable characteristics for biomedical applications because of their high biocompatibility, specific strength, and corrosion resistance [3-4]. Commercially pure titanium is currently used in clinics, although it has disadvantages of low strength, difficulty in polishing, and poor wear resistance. Therefore, this material is still insufficient for high-stress applications, such as long-spanned fixed prostheses and the frameworks of removable partial dentures [5-8]. The modulus of Ti-6Al-4V (110 GPa) is much lower than that of $\mathrm{Co}-\mathrm{Cr}-\mathrm{Mo}(230 \mathrm{GPa})$ and stainless steel $(205 \mathrm{GPa})$, which are used for biomedical applications. However, the modulus of Ti-6Al-4V remains much higher than that of human cortical bone (10-30 GPa) $[9,10]$. Finite element analysis suggests that joint replacements may better stimulate the femur in terms of distribution stress to the adjacent bone tissues if a lower modulus material is used [11]. The relatively low moduli of Ti alloys make them strong candidates for reducing the stress shielding effect. Alternatively, the powder metallurgy (PM) process has the advantage of a free shape design and contributing to a fine, homogenous microstructure [12]. Titanium can be alloyed with a variety of elements to alter the following of its properties: to improve its strength, high-temperature performance, creep resistance, weldability, and formability [13]. Molybdenum (Mo) is a non-toxic and allergy-free element that is commonly used for alloying because of its strong resistance to corrosion [14]. Recently, Zhou et al. 
[15] and Oliveira et al. [16] reported that Ti-Mo alloys have excellent biocompatibility and corrosion resistance. Chen et al. [17] investigated the microstructure, mechanical properties and wear resistance of binary $\mathrm{Ti}-5 \mathrm{Mo}$ used for dental applications. However, its properties were insufficient for clinical applications. Because the properties of $\mathrm{Ti}$ alloys are sensitive to the phases and crystal structure of the metal and certain phases may be stabilized by the addition of alloying elements, alloying may enhance the mechanical properties of titanium. Additionally, the $\mathrm{Zr}$ element shows superior corrosion resistance and satisfactory biocompatibility [18]. A Ti- 10Zr alloy with greater hardness than the unalloyed titanium was developed. However, its mechanical properties remained insufficient for clinical dental and orthopedic applications. Another study investigated a series of $\mathrm{Ti}-10 \mathrm{Zr}-\mathrm{xCr}$ alloys containing a $\mathrm{Cr}$ content that ranged from 1 to $10 \mathrm{wt}$ \%. Experimental results indicated that the crystal structure and mechanical properties of the cast alloys were sensitive to their $\mathrm{Cr}$ content [18]. The addition of chromium also contributed to the stabilization of the beta phase, by a factor 1.6, according to the Mo equivalent equation. In this study, chromium (Cr) was selected as an alloying element because it controls the anodic activity of the alloy and increases the tendency of titanium to passivate [19]. In fact, $\mathrm{Cr}$ has been used for many years in dental casting alloys [20]. Additionally, Cr is one of the stronger $\beta$ phase stabilizers and it has a significant influence on the properties of other titanium systems. Depending on the amount of $\mathrm{Cr}$ and cooling speed, the $\beta$ phase can be retained in the as-cast structure [21]. In fact, $\mathrm{Cr}$ has already been used for many years as a major constituent in dental casting alloys [22]. Syarif et al. explored the stabilization of the $\beta$ phase with the addition of different $\mathrm{Cr}$ contents on Ti18Mo alloys [23] as well as the influence of oxygen in the microstructure of the Ti18Mo10Cr alloy obtained by powder metallurgy [24]. In the current study, the effects of $\mathrm{Cr}$ on the microstructure and mechanical properties of a $\mathrm{Ti}-15 \mathrm{Mo}-6 \mathrm{Zr}$ based alloy were investigated in an effort to develop new alloys for biomedical applications.

\section{MATERIALS AND METHODS}

\subsection{Alloy preparation and characterization}

The different characteristics of the metal powders, $\mathrm{Ti}, \mathrm{Mo}, \mathrm{Zr}$, and $\mathrm{Cr}$, used for the synthesis are presented in Table 1.

Table 1: Ti, Mo, Zr, and Cr powder characteristics.

\begin{tabular}{cccc}
\hline Powder & Supplier & Purity (\%) & Powder size (mesh) \\
\hline Titanium & Phelly & 99.7 & -325 \\
Molybdenum & Atlantic Equipment & 99.98 & -250 \\
& Engineering & & \\
\cline { 1 - 1 } Zirconium & Alfa Aesar & 99.6 & -325 \\
\cline { 1 - 1 } chromium & Alfa Aesar & 99.8 & -325 \\
\hline
\end{tabular}

In the frame of this study, the 5 subsequent alloy compositions were prepared: $\mathrm{Ti}-15 \mathrm{Mo}-6 \mathrm{Zr}, \mathrm{Ti}-15 \mathrm{Mo}-6 \mathrm{Zr}-1 \mathrm{Cr}$, $\mathrm{Ti}-15 \mathrm{Mo}-6 \mathrm{Zr}-2 \mathrm{Cr}$, Ti-15Mo-6Zr-3Cr and $\mathrm{Ti}-15 \mathrm{Mo}-6 \mathrm{Zr}-4 \mathrm{Cr}$ (in weight \%). The different starting powders were dry mixed by ball milling at $200 \mathrm{rpm}$ and $30 \mathrm{~min}$ and then compacted into a rectangle $(5 \mathrm{~mm}$ high, $12 \mathrm{~mm}$ width, and $30 \mathrm{~mm}$ length) with a cold uniaxial compacting machine (Instron 432 Model with a load cell of 500kN) under a pressure of $600 \mathrm{MPa}$. To avoid reactions of titanium with atmospheric oxygen and nitrogen, sintering was performed under a high purity argon atmosphere. This atmosphere was obtained after 5 cycles of primary vacuum and argon refilling. Green compact samples were sintered under a high vacuum (approximately $10^{-4}$ to $10^{-5} \mathrm{mbar}$ ) in a tubular furnace Carbolite HVT 15/75/450 model, at $1250^{\circ} \mathrm{C}$ after a dwell time of $3 \mathrm{~h}$ in a medium frequency induction horizontal furnace and naturally cooled at $10^{\circ} \mathrm{C} / \mathrm{min}$. Each composition was successively polished with 220,500 , and 1000 grit $\mathrm{SiC}$ abrasive papers. All polished samples were cleaned by immersion for $30 \mathrm{~min}$ in alcohol and 30 min in distilled water using an ultrasonic cleaner and sterilized in a Poupinel furnace. To evaluate the shrinkage, the volume of each sample was measured before and after sintering. The surfaces of the alloys for this microstructural study were mechanically polished via a standard metallographic procedure to a final level of $0.3 \mu \mathrm{m}$ alumina powder. For microstructural characterization, a transverse section of the sintered samples was cut and metallographically prepared. The microstructure was observed using an optical microscope, Nikon LV100. To quantify the phases and internal porosity, NIS-Elements ${ }^{\circledR}$ image analysis software was used. Backscattered electron images (BSE) of the microstructures at different magnifications were obtained with a scanning electron microscope Jeol JSM6300. Microanalysis was performed using energy dispersive spectroscopy (EDS) to quantify the chemical composition. The microhardness values of the polished alloys were determined according to the ASTM: E384 method using a microhardness tester (MVK-E3, Mitutoyo, Japan) set at $0.98 \mathrm{~N}$ for 15 sin combinations with EBSD 
to analyze the elemental partitioning. Three-point bending tests were performed using a desktop mechanical tester (AG-IS, Shimadzu, Japan) according to ASTM: E855. The bending strengths were determined using the equation, $\sigma$ $=3 \mathrm{PL} / 2 \mathrm{bh}^{2}$, where $\sigma$ is the bending strength $(\mathrm{MPa}), \mathrm{P}$ the load $(\mathrm{N}), \mathrm{L}$ the span length $(\mathrm{mm}), \mathrm{b}$ the specimen width $(\mathrm{mm})$, and $\mathrm{h}$ the specimen thickness $(\mathrm{mm})$. The dimensions of all specimens were $\mathrm{L}=30.0 \mathrm{~mm}, \mathrm{~b}=12.0 \mathrm{~mm}$, and $\mathrm{h}$ $=5.0 \mathrm{~mm}$. The average bending, compression strength and modulus of elasticity were collected at least 5 samples under each condition. After the bending test, the Elastic modulus (Young's modulus E) of the designed alloy was determined using an ultrasonic method from the density $(\rho)$ and from the measurements of the longitudinal $V_{L}$ and transversal $\mathrm{V}_{\mathrm{T}}$ wave velocities. A piezo-electric transducer $(10 \mathrm{MHz})$, in contact with the sample via a coupling gel, was used for these measurements. As a result, the value of Young's modulus for the infinite mode can be obtained from:

$$
E=\rho \frac{3 V_{L}^{2}-4 V_{T}^{2}}{\frac{V_{L}^{2}}{V_{T}^{2}}-1}
$$

And, the fractured surface of the specimen was observed with scanning electron microscopy (SEM; JSM-6700F, JEOL, Japan).

\section{RESULTS AND DISCUSSION}

\subsection{The shrinkage}

The density of the sintered alloys is directly determined from the weight, $W_{\text {sint }}$, and volume, $V_{\text {sint }}$, measurements after sintering:

$$
\rho_{\text {sint }}=\frac{W_{\text {sint }}}{V_{\text {sint }}}
$$

It should be noticed that no significant weight loss was observed between the green compact and sintered alloy. Thus from Eq. (2), the porosity (in \%) of each alloy is evaluated using the following calculation:

$$
\% \text { porosity }=\frac{\rho_{\text {bulk }}-\rho_{\text {sint }}}{\rho_{\text {bulk }}}
$$

To characterize the densification, the volume (or dimension) loss percentage (shrinkage) of each sample after sintering was measured:

$$
\% \text { loss }=\frac{V_{\text {green }}-V_{\text {sint }}}{V_{\text {geen }}} x 100
$$

The results (\%porosity and \%loss) obtained for each alloy are reported in Figure 1. No significant differences in the porosity percentage (evaluated at about $1.7 \%-2.8 \%$ ) were observed between the alloys. These results are confirmed by the volume shrinkage measurements. The dimension loss is observed to be $16-20 \%$ for $\mathrm{Ti} 15 \mathrm{Mo} \mathrm{Zr}$, Ti15Mo6Zr1Cr, Ti15Mo6Zr2Cr and Ti15Mo6Zr4Cr alloys as well as $16 \%$ for Ti15Mo6Zr3Cr. However, the addition of low chromium levels decreased, at least initially, the pore content, which later increased with the addition of chromium, resulting in a Ti15Mo6Zr2Cr alloy the lower porosity. Similarly, the pore size and shape were evaluated; the results are shown in Table 2, showing again that the addition of $2 \%$ chromium enables adequate diffusion of the element in the base alloy by minimizing both the porosity and size, although there were no significant differences. In all cases, the standard deviation of the pore size exceeded its average value; also, the circularity obtained by the ratio of area and perimeter thereof, with respect to the value of the circle, is very similar. 


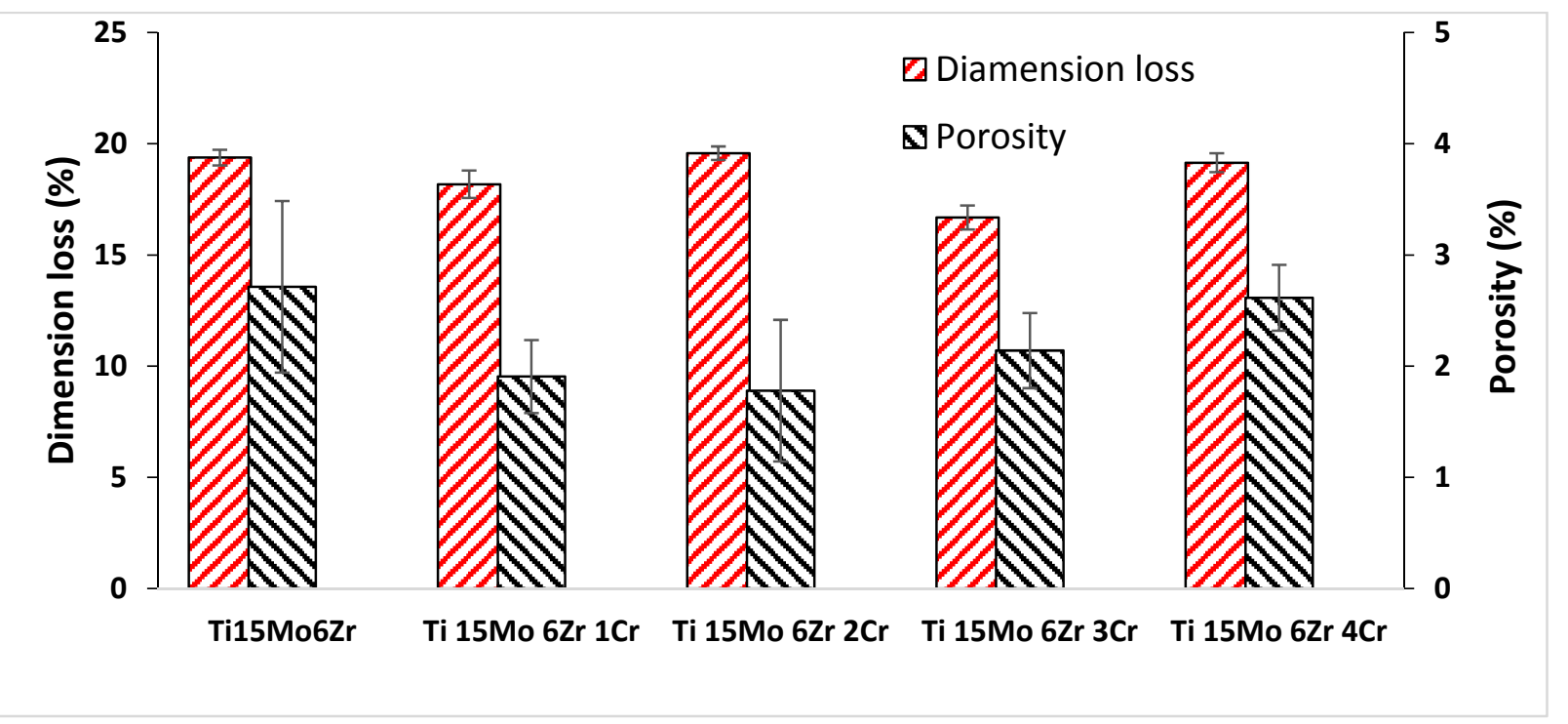

Figure 1. Volume loss and porosity (in \%) after the sintering of each alloy composition.

Table 2. Dimensions and shape of the pores in Ti15Mo6Zr xCr alloys, as determined by optical microscopy.

\begin{tabular}{cccc}
\hline Alloy code & $\begin{array}{c}\text { Internal } \\
\text { porosity }(\%)\end{array}$ & $\begin{array}{c}\text { Pore Size } \\
(\mu \mathrm{m})\end{array}$ & Pore circularity \\
\cline { 1 - 3 } Ti15Mo6Zr & $4.71 \pm 0.56$ & $6.04 \pm 4.10$ & 0.84 \\
\cline { 1 - 1 } Ti 15Mo 6Zr 1Cr & $4.94 \pm 0.49$ & $4.38 \pm 4.27$ & 0.86 \\
\cline { 1 - 1 } Ti 15Mo 6Zr 2Cr & $2.74 \pm 0.89$ & $4.05 \pm 5.82$ & 0.86 \\
\cline { 1 - 1 } Ti 15Mo 6Zr 3Cr & $4.42 \pm 0.34$ & $8.31 \pm 8.60$ & 0.83 \\
\cline { 1 - 1 } Ti 15Mo 6Zr 4Cr & $4.21 \pm 0.64$ & $9.00 \pm 12.94$ & 0.82 \\
\hline
\end{tabular}

\subsection{Phase identification}

Experimental results of this study indicate that the crystal structures of the Ti $15 \mathrm{Mo} 6 \mathrm{Zr}$ are strongly affected by the addition of Cr. Figure 2 shows the XRD patterns of Ti $15 \mathrm{Mo} 6 \mathrm{Zr}$ and the series of ternary Ti $15 \mathrm{Mo} 6 \mathrm{Zr}$ xCr alloys. The Ti 15Mo 6Zr alloy mainly consisted of the $\alpha^{\prime}+\beta$ phase. When $1 \mathrm{wt} . \% \mathrm{Cr}$ or greater was added, the $\beta$ phase was entirely retained with a bcc crystal structure because the alloying element $\mathrm{Cr}$ is known to act as a $\beta \mathrm{Ti}-\mathrm{Zr}-\mathrm{xCr}$ [25], $\mathrm{Ti}-10 \mathrm{Zr}-\mathrm{xCr}[18]$ and $\mathrm{Ti}-5 \mathrm{Mo}-\mathrm{xCr}[22]$.

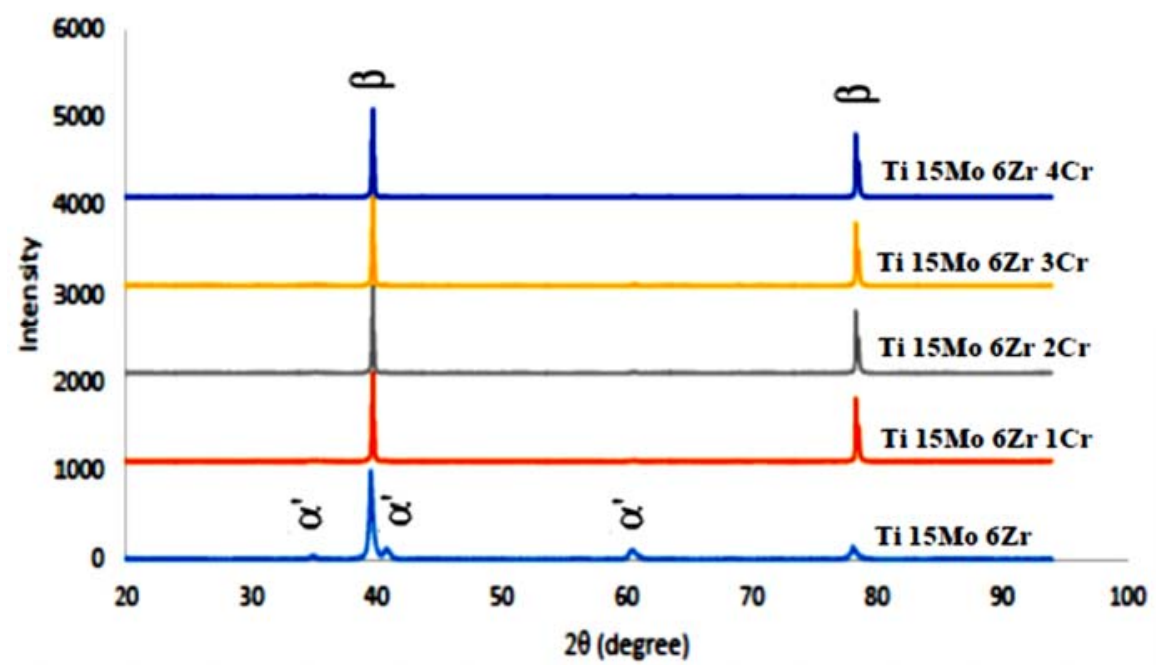

Figure 2. X-ray diffraction patterns for the sintering Ti $15 \mathrm{Mo} 6 \mathrm{Zr}$ and $\mathrm{Ti} 15 \mathrm{Mo} 6 \mathrm{Zr} \mathrm{xCr}$ alloys. 


\subsection{Microstructure}

Figure 3 shows typically etched microstructures of Ti $15 \mathrm{Mo} 6 \mathrm{Zr}$ and the series of $\mathrm{Ti} 15 \mathrm{Mo} 6 \mathrm{Zr} \mathrm{xCr}$ alloys under an optical microscope. As shown in Fig. 3(a), the microstructure of the Ti 15Mo 6Zr alloy appears to be an $(\alpha+\beta)$ structure. In contrast to the $\mathrm{Ti} 15 \mathrm{Mo} 6 \mathrm{Zr} \times \mathrm{Cr}$ alloy, the microstructures of the $\mathrm{Ti} 15 \mathrm{Mo} 6 \mathrm{Zr} 2 \mathrm{Cr}$ alloy appeared to consist of $\beta$ phase grains, as shown in Figure 3(b). In other words, in the Ti-Cr alloy system, the $\beta$ phase can be entirely retained upon fast cooling when the $\mathrm{Cr}$ content increases. The average $\beta$ phase grain sizes of the Ti $15 \mathrm{Mo}$ 6Zr and Ti 15Mo 6Zr xCr series alloys, according to ASTM E 112 - 96 Standard Test Methods for determining the average grain size, are shown in Table 3. As indicated in the Table, the average $\beta$ phase grain sizes decreased with increasing $\mathrm{Cr}$ content. Additionally, the relative density and phase distribution of the samples were obtained from images taken with an optical microscope using an image analysis program in Table 3.

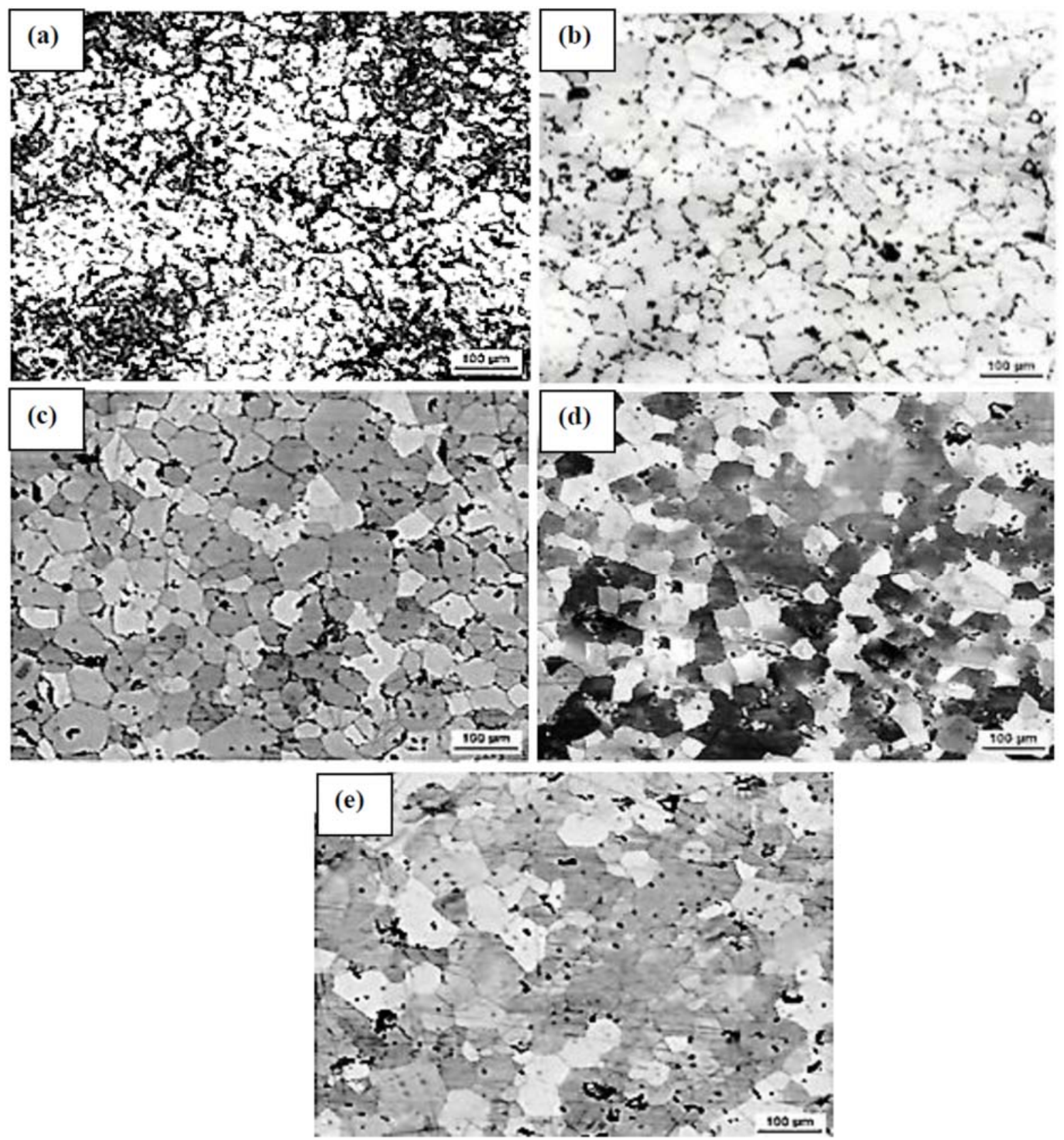

Figure 3. Optical micrographs of alloys (a) Ti15Mo6Zr, (b) Ti15Mo6Zr1Cr, (c) Ti15Mo6Zr2Cr, (d) Ti15Mo6Zr3Cr, and (e) Ti15Mo6Zr4Cr. 
Table 3: Relative density (in \%), grain size and phase distribution of each alloy composition by optical microscopy.

\begin{tabular}{|c|c|c|c|c|}
\hline Alloy code & $\begin{array}{l}\text { Relative } \\
\text { density } \\
\text { in }(\%)\end{array}$ & $\begin{array}{c}\beta \text { grain size } \\
(\mu \mathrm{m})\end{array}$ & $\begin{array}{r}\text { Phase } \\
\% \alpha \text {-phase }\end{array}$ & $\begin{array}{l}\text { distribution } \\
\% \beta \text {-phase }\end{array}$ \\
\hline Ti15Mo6Zr & $97.29 \pm 0.82$ & $50.36 \pm 3.10$ & $3.60 \pm 0.26$ & $96.40 \pm 0.26$ \\
\hline Ti $15 \mathrm{Mo} 6 \mathrm{Zr} 1 \mathrm{Cr}$ & $97.89 \pm 0.33$ & $46.66 \pm 2.40$ & $1.30 \pm 0.23$ & $98.70 \pm 0.23$ \\
\hline Ti $15 \mathrm{Mo} 6 \mathrm{Zr} 2 \mathrm{Cr}$ & $98.77 \pm 0.64$ & $42.50 \pm 3.42$ & $1.10 \pm 0.12$ & $98.90 \pm 0.12$ \\
\hline Ti $15 \mathrm{Mo} 6 \mathrm{Zr} 3 \mathrm{Cr}$ & $97.86 \pm 0.34$ & $43.92 \pm 1.55$ & $1.20 \pm 0.15$ & $98.80 \pm 0.15$ \\
\hline Ti $15 \mathrm{Mo} 6 \mathrm{Zr} 4 \mathrm{Cr}$ & $97.39 \pm 0.30$ & $45.21 \pm 3.12$ & $1.30 \pm 0.22$ & $98.70 \pm 0.22$ \\
\hline
\end{tabular}

\subsection{Scanning electron microscopy / energy dispersive spectrometry (SEM/EDS).}

Compositions of the series of Ti15Mo6Zr xCr alloys determined by scanning electron microscopy / energy dispersive spectrometry (SEM/EDS) are listed in Table 4. Figure 4 shows the BSE-SEM micrographs of Ti 15Mo 6Zr and Ti 15Mo 6Zr xCr alloys. As shown in Fig. 4(a), the BSE-SEM micrograph of the Ti 15Mo 6Zr alloy appears to be an $\alpha$ and $(\alpha+\beta)$ structure. In contrast to the Ti $15 \mathrm{Mo} 6 \mathrm{Zr} \times \mathrm{Cr}$ alloy, the BSE-SEM micrographs of the other alloys appeared to consist of $\beta$ phase grains, as shown in Figure 4 (b, c, d, and f).
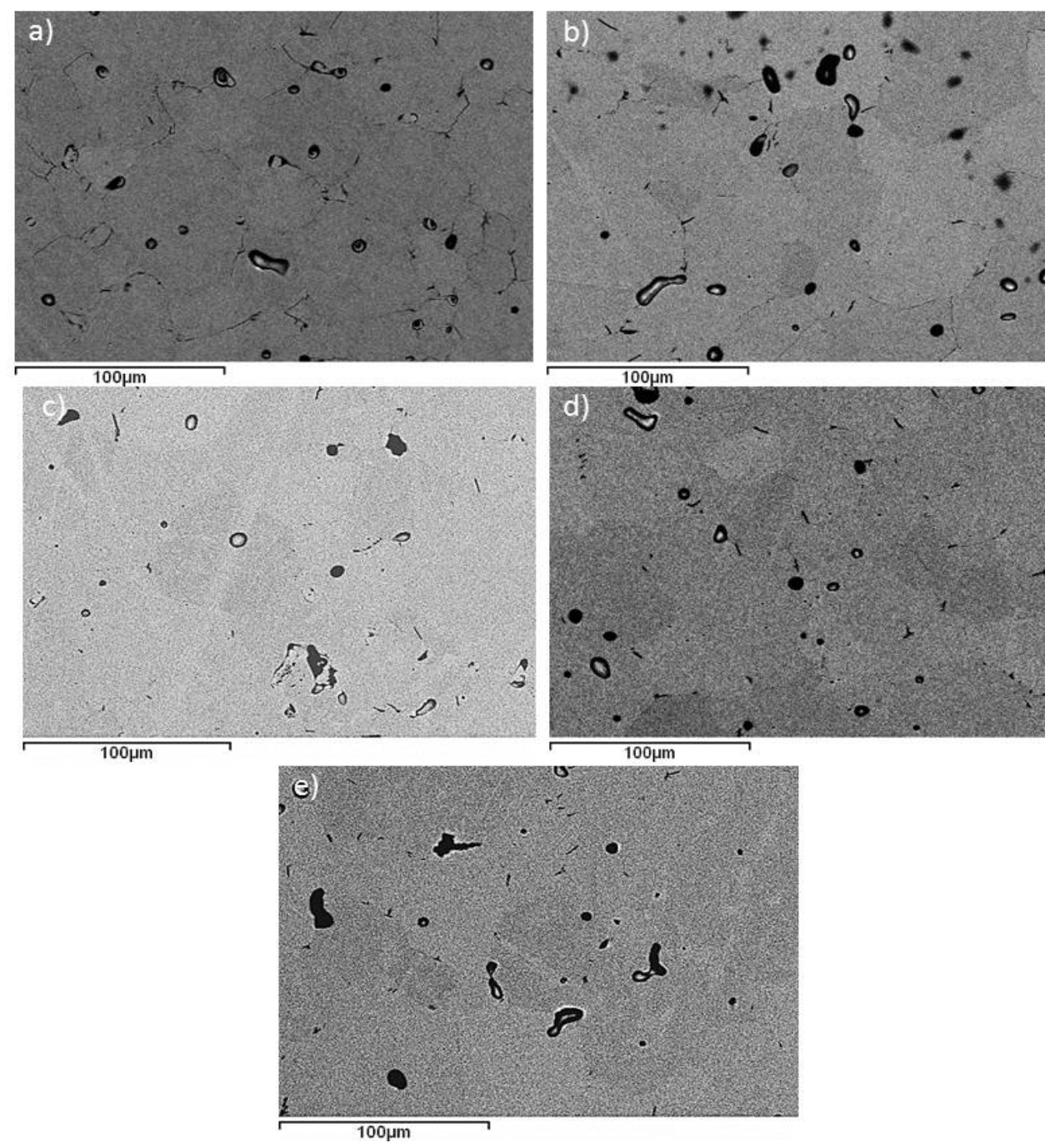

Figure 4.BSE-SEM micrographs of alloys. (a) Ti15Mo6Zr, (b) Ti15Mo6Zr1Cr,

(c) Ti15Mo6Zr2Cr, (d) Ti15Mo6Zr3Cr, and (e) Ti15Mo6Zr4Cr. 
Table 4: EDS-determined alloy compositions for the study.

\begin{tabular}{ccccc}
\hline Alloy code & Ti (wt. \%) & Mo (wt. \%) & Zr (wt. \%) & Cr (wt. \%) \\
\cline { 1 - 4 } Ti15Mo6Zr & $77.74 \pm 0.02$ & $15.99 \pm 0.05$ & $6.27 \pm 0.01$ & --- \\
\cline { 1 - 3 } Ti 15Mo 6Zr 1Cr & $76.44 \pm 0.45$ & $16.22 \pm 0.48$ & $6.39 \pm 0.16$ & $0.94 \pm 0.19$ \\
\cline { 1 - 3 } Ti 15Mo 6Zr 2Cr & $75.61 \pm 0.01$ & $16.16 \pm 0.09$ & $6.32 \pm 0.02$ & $1.93 \pm 0.12$ \\
\cline { 1 - 3 } Ti 15Mo 6Zr 3Cr & $74.36 \pm 0.14$ & $16.11 \pm 0.10$ & $6.54 \pm 0.18$ & $3 \pm 0.14$ \\
\cline { 1 - 3 } Ti 15Mo 6Zr 4Cr & $73.93 \pm 0.15$ & $15.86 \pm 0.12$ & $6.38 \pm 0.16$ & $3.83 \pm 0.15$ \\
\hline
\end{tabular}

A good distribution of the alloying elements is confirmed by EDS in these transition areas, as shown in Figure 5. In this case, the gradient in the microstructure morphology along the sample's radial direction might be associated with the stability of the $\beta$ phase. A method based on the EBSD measurements was used to identify the phase transformation of the Ti 15Mo 6Zr 2Cr alloy. Figure 6 presents EBSD analyses in terms of the (IPF) and phase maps of Ti $15 \mathrm{Mo} 6 \mathrm{Zr} 2 \mathrm{Cr}$. EBSD measurements were performed to identify and index the fine $\alpha / \beta$ structures. The image quality and phase maps show the different dispersions and morphologies of $\alpha$ and $\beta$ as well as the IPF maps for the corresponding orientations of $\alpha$ and $\beta$, respectively. From the EBSD results, the $\alpha$ phase is a grain boundary indicated according to the color key of the standard triangle.
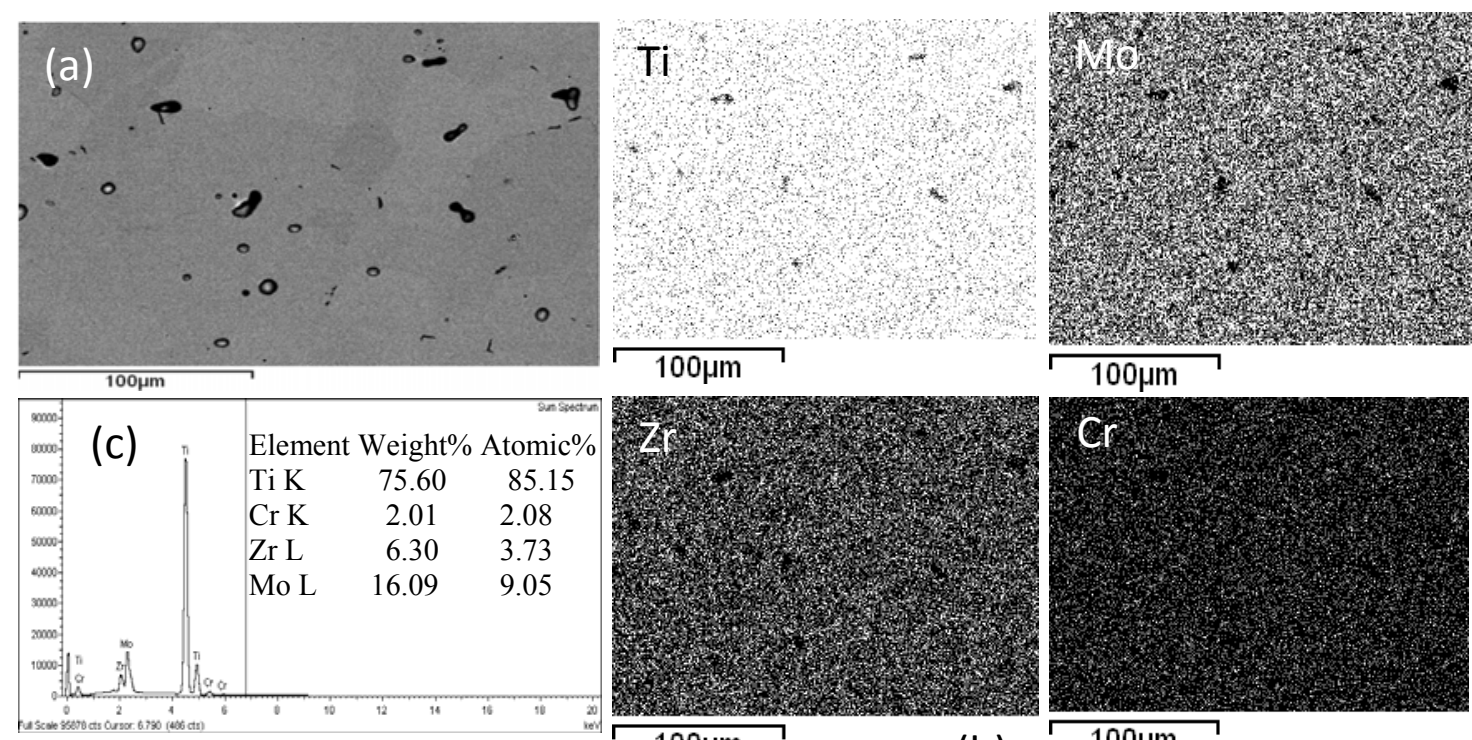

$100 \mu \mathrm{m}$

(b)

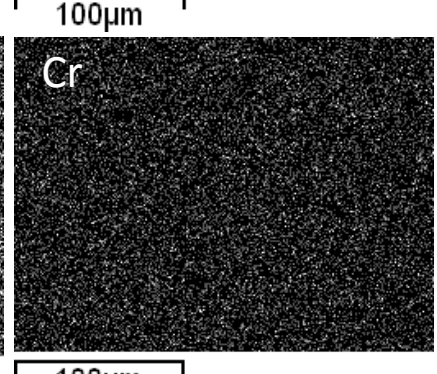

Figure 5. High magnification SEM-BSE micrograph of the (a) Ti15Mo6Zr 2Cr alloy showing a microstructure observed in a transition area within the microstructural gradient; (b) mapping analysis of the area, confirming a homogeneous distribution of the alloying elements; and (c) its EDX. 

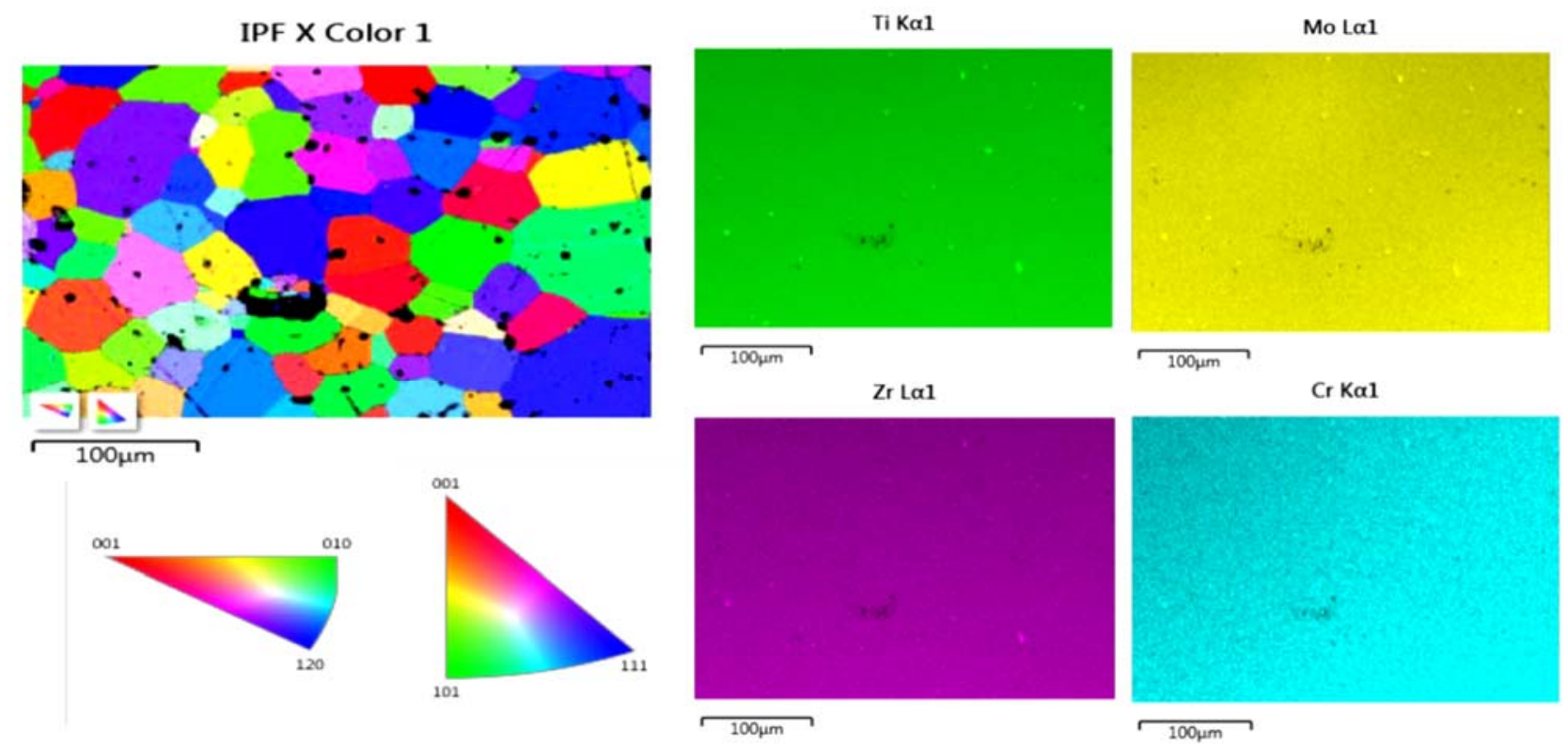

Figure 6. IPF EBSD maps of Ti 15Mo $6 \mathrm{Zr} 2 \mathrm{Cr}$ alloy showing the $\beta$ phase microtexture at phase transformation.

\subsection{Microhardness}

The microhardness values of $\mathrm{Ti} 15 \mathrm{Mo} 6 \mathrm{Zr}$ and the series of $\mathrm{Ti} 15 \mathrm{Mo} 6 \mathrm{Zr}$ xCr alloys are shown in Figure 7 . The values of Ti $15 \mathrm{Mo} 6 \mathrm{Zr}$ and all Ti $15 \mathrm{Mo} 6 \mathrm{Zr}$ xCr samples $(368-412 \mathrm{HV})$ are similar to those reported by Syarif et al. [23]. The microhardness measurements did not reveal any significant influence of the chemical composition. Ti $15 \mathrm{Mo} 6 \mathrm{Zr} 2 \mathrm{Cr}$, with the largest $\beta$ phase quantity, results from the lower quantity of the porosity content of this alloy, which exhibited the greatest microhardness values $(412 \mathrm{HV})$.

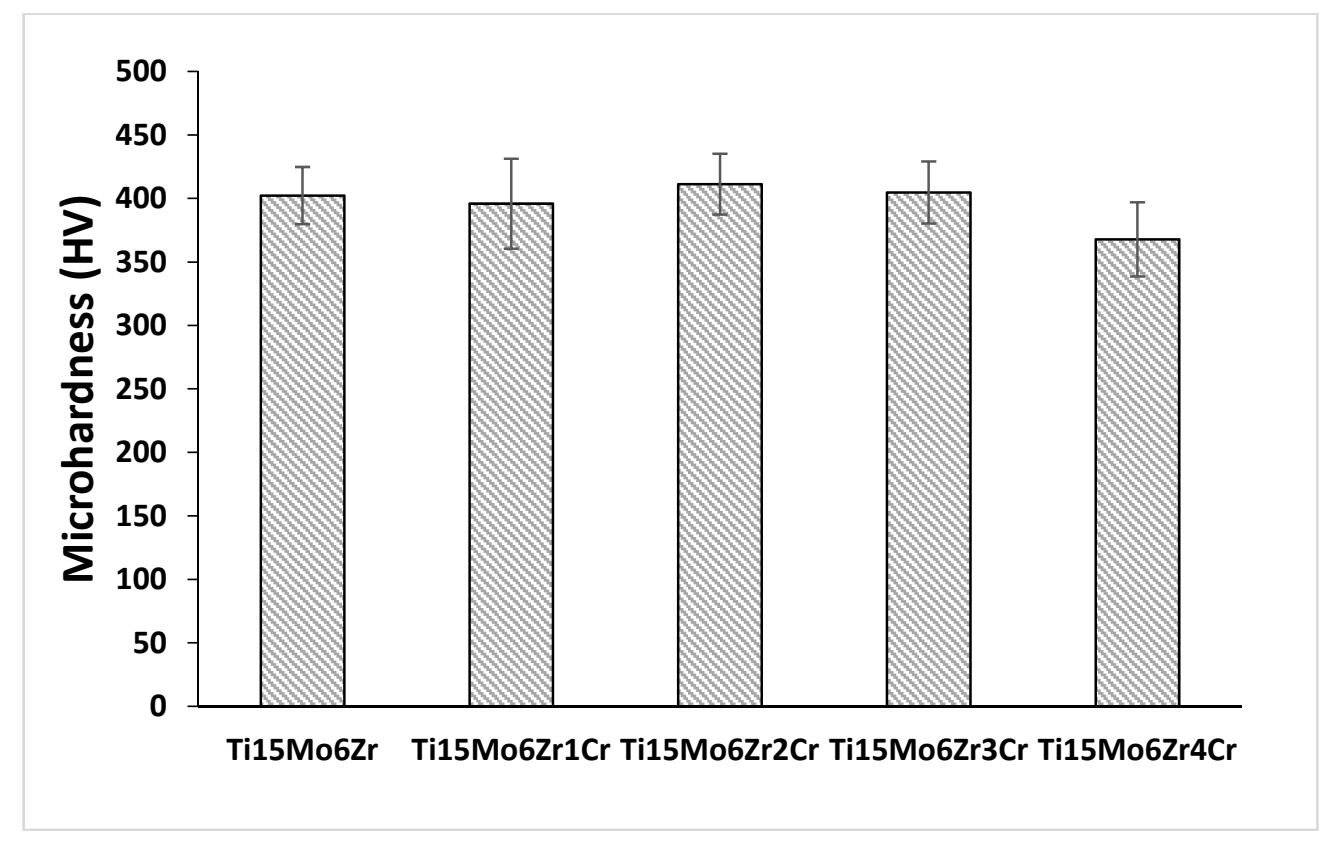

Figure 7. Microhardness of Ti 15Mo 6Zr and Ti 15Mo 6Zr xCr alloys.

\subsection{Mechanical properties}

The typical bending and compression stress-strain curves of Ti15Mo6Zr and Ti15Mo6ZrxCr alloys are shown in Figure 8 (a and b, respectively). In this study, all Ti15Mo6Zr and Ti15Mo6ZrxCr alloys 
exhibited ductile properties. However, with 1-4 wt. \% Cr, retention of the metastable $\beta$ phase began. The results of the elastic modulus are very important for biomaterials, and the elastic modulus should be closer to that of human bone. Figure 9 illustrates the effect of chromium content on the compression and bending strength of the Ti15Mo6Zr base alloy. Ti15Mo6ZrxCr alloys had significantly lower bending and compression strengths (1440-1313 and $875-1160 \mathrm{MPa}$, respectively) than Ti15Mo6Zr (1660 and 1200 $\mathrm{MPa}$, respectively). The strength of Ti15Mo6Zr was approximately 1.11 times greater than that of Ti15Mo6ZrxCr. The elastic, compression and bending moduli results are shown in Figure 10. The elastic modulus of Ti15Mo6Zr1Cr (92 GPa), Ti15Mo6Zr2Cr (86 GPa), Ti15Mo6Zr3Cr (90 GPa), and Ti-5Mo4Cr (91 GPa) had a significantly lower elastic modulus than Ti15Mo6Zr (99GPa) alloys, respectively, as shown in table 4 . The elastic modulus of the Ti15Mo6Zr base alloy was approximately 1.15 times greater than that of Ti15Mo6Zr2Cr. The Ti-15Mo-6Zr-2Cr alloy had lower bending and compression moduli (31 and $23 \mathrm{GPa}$, respectively) than Ti-15Mo-6Zr-based alloys (40 and $36 \mathrm{GPa}$, respectively). Moreover, Ti$15 \mathrm{Mo}-6 \mathrm{Zr}-2 \mathrm{Cr}$ alloys exhibited higher bending and compression strength/modulus ratios that were as large as 48.4 and 52.2, respectively, which are higher than those of the Ti-15Mo-6Zr-based alloy (41.3 and 33.6, respectively). The results of the elastic modulus are very important in the biomaterials; they should be closer to the modules of human bone. Although the interpretation of the measured modulus values is not fully understood, it seems that several different mechanisms, such as the phase and solute effect are competing to determine a modulus of the alloy. Ho et al. [26] stated that the dependence of the modulus had a more sensitive effect on the phase/crystal structure than on other factors. It is widely known that the $\beta$ phase Ti alloys generally have a lower modulus level than the $\alpha$ or $\alpha+\beta$ phase-type alloys [22-26]. Additionally, the Ti15Mo6Zr2Cr alloy had the lowest elastic, compression and bending moduli, which were lower than that of the Ti15Mo6Zr base alloy. They indicated that the orthorhombic has a lower modulus. As mentioned in Introduction to this study, the use of implant materials with lower moduli (closer to that of a human bone) can reduce the stress-shielding effect. Additionally, implants bearing heavy loads must be strong and durable enough to withstand their physiological responsibilities over the years [22-26]. As such, achieving high strength under the conditions of a low elastic modulus that is close to the modulus of the implant's surrounding bone is central to alloy development. In a study by W.F. Ho [14], a bending strength/modulus ratio (x1000) was used to evaluate an indication of feasibility for use as an implant material. In this study, the $\beta$-phase Ti15Mo6Zr2Cr alloy exhibited the highest bending strength/modulus ratio, and $\mathrm{Cr}$ is one of the strongest $\beta$ phase stabilizers, which has a significant influence on the properties of other titanium systems. The high strength/modulus ratio of the Ti15Mo6Zr2 $\mathrm{Cr}$ demonstrates its advantages for use as an implant material.
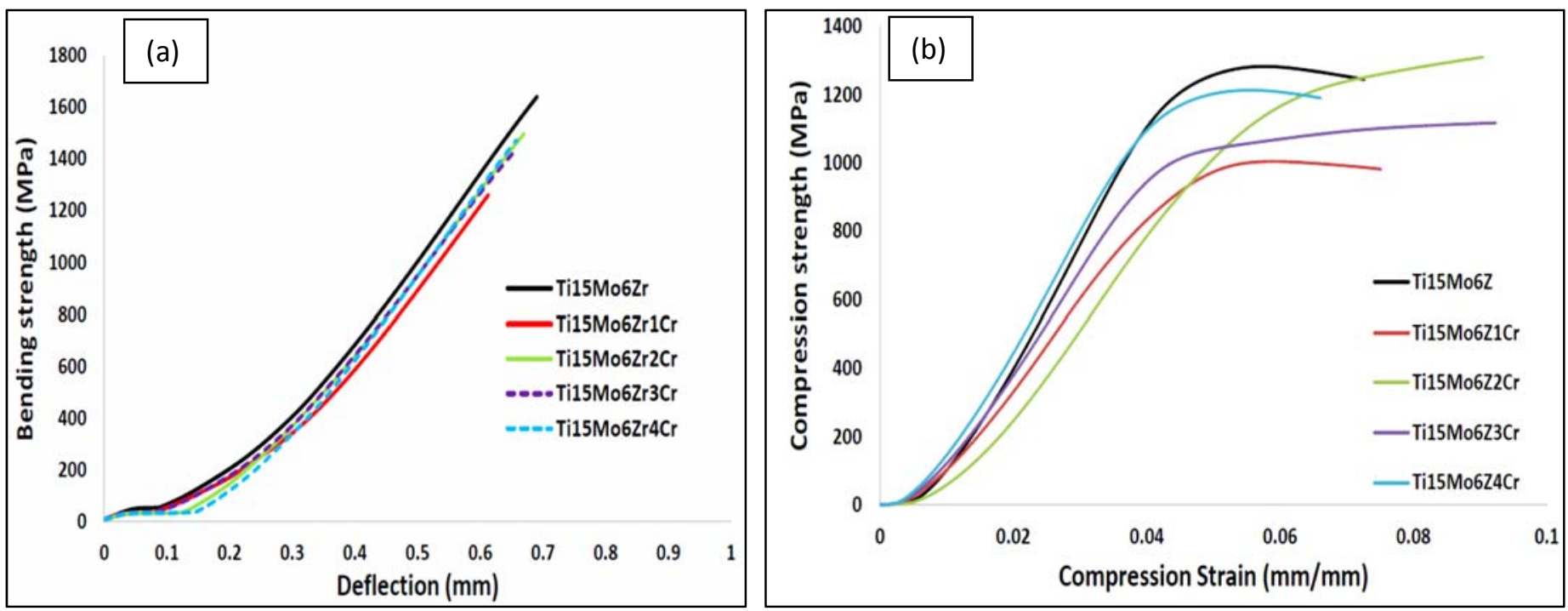

Figure 8. (a) Bending and (b) Compression stress-strain curves of Ti15Mo6Zr and Ti15Mo6Zr $\mathrm{xCr}$ alloys. 


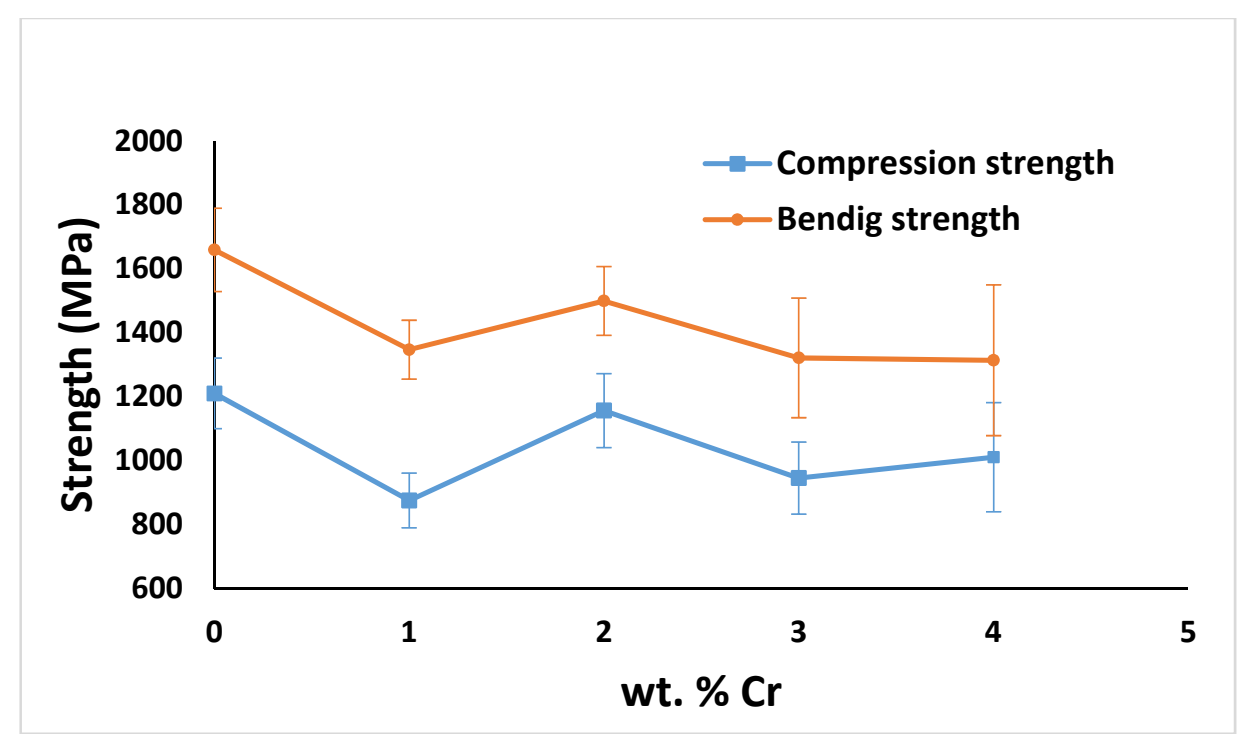

Figure 9. Strength of Ti 15Mo 6Zr and Ti 15Mo 6Zr xCr alloys.

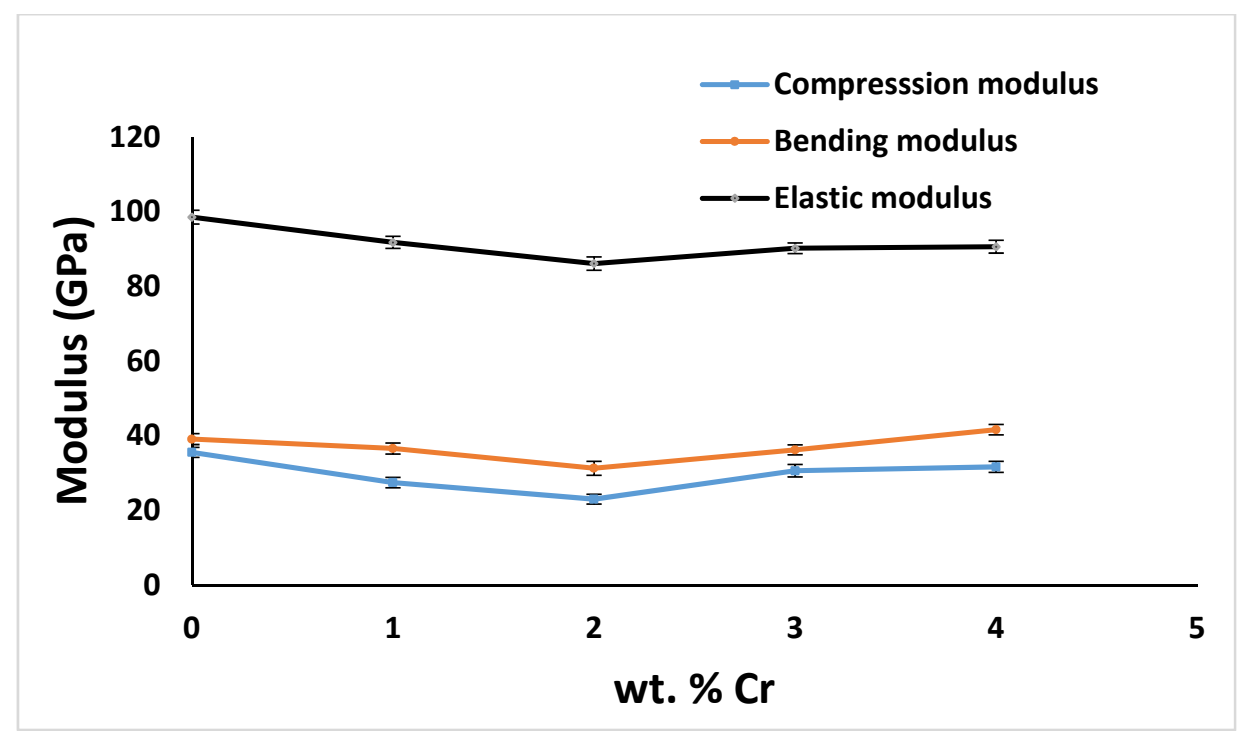

Figure 10. Moduli of Ti 15Mo 6Zr and Ti 15Mo6Zr xCr alloys.

\subsection{Fractured surface topography}

The effect of the chromium content and $\beta$ phase on Ti15Mo6Zr-based alloy can also be observed in fractographs of this alloy. Figure 8 shows SEM micrographs of the fractured surfaces of Ti $15 \mathrm{Mo} 6 \mathrm{Zr}$ and Ti15Mo6Zr xCr after bending tests. As shown in Fig. 8a, Ti15Mo6Zr was characterized by cleavage facets in the fractured surface, which are characteristic of the decreased ductility. The cleavage fracture corresponds to the brittleness of the specimen. The fractured structures of Ti15Mo6Zr 1Cr (Fig.8b) consist of a few dimples and cleavage planes, meaning that the fracture process of this alloy is a mixture of brittle and plastic mechanisms. As shown in Fig. 8c, the fractured structures of the Ti15Mo6Zr 2Cr alloy exhibited mainly dimple ruptures and a few cleaved grains, which is indicative of a typical ductile fracture. Compared with $\mathrm{Ti} 15 \mathrm{Mo} 6 \mathrm{Zr} 1 \mathrm{Cr}$, the cleavage planes of $\mathrm{Ti} 15 \mathrm{Mo} 6 \mathrm{Zr} 3 \mathrm{Cr}$ (Fig. 8d) and Ti15Mo6Zr 4Cr (Fig. 8e) increase in size, indicating that the latter is more brittle than the former. This result is in accordance with the change in the lower value of bending deflection and compression stain (less than approximately $0.7 \mathrm{~mm}$ and $0.08 \mathrm{~mm} / \mathrm{mm}$, respectively). 

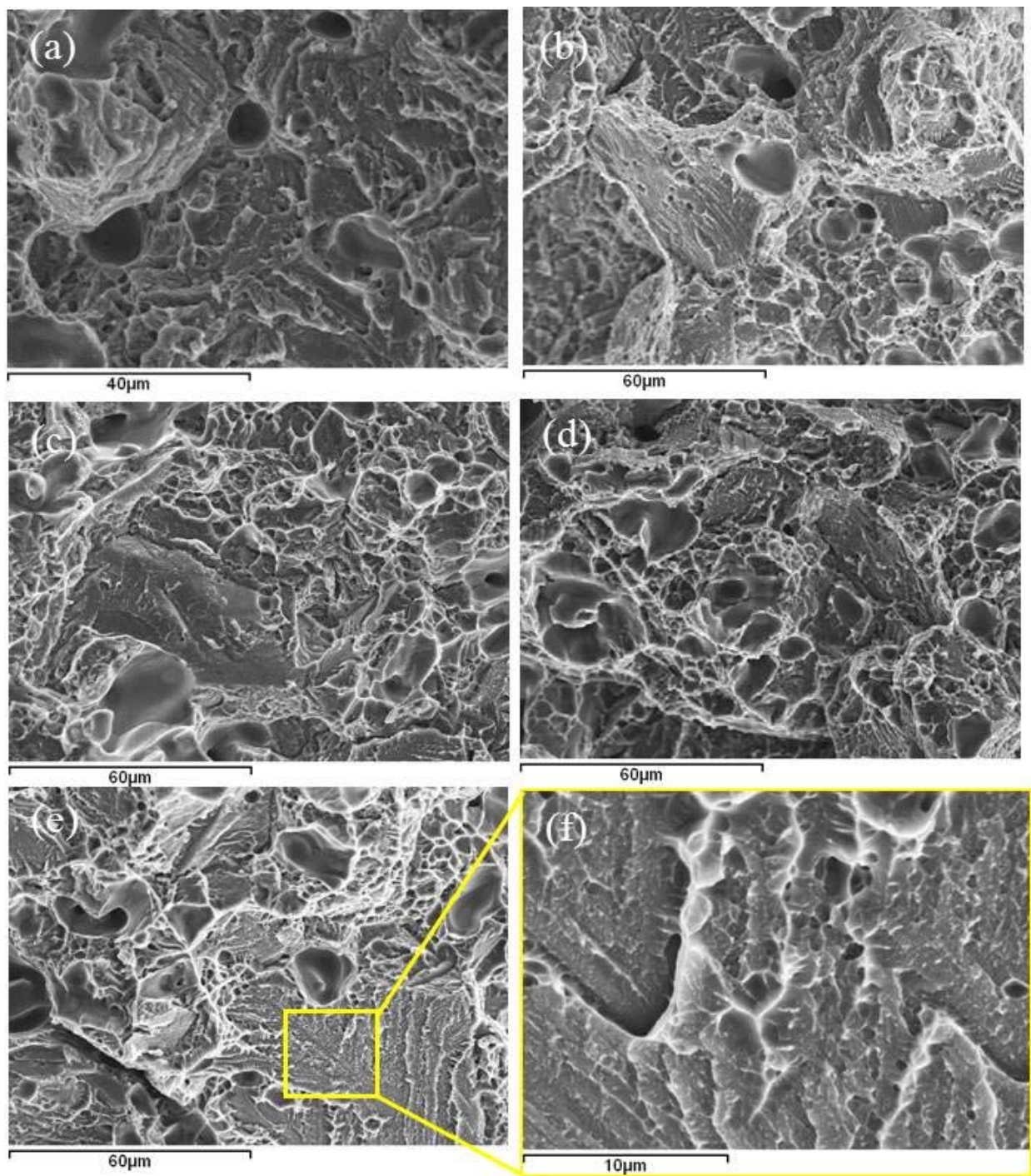

Figure 8. SEM fractographs of (a) Ti 15 Mo 6Zr, (b) Ti 15Mo 6Zr 1Cr, (c) Ti 15Mo 6Zr 2Cr, (d) Ti 15Mo 6Zr 3Cr, and (e) Ti 15Mo 6Zr 4Cr alloys; (f) higher magnification of the area marked by the rectangle in (e).

\section{CONCLUSIONS}

The effects of the $\mathrm{Cr}$ contents on the microstructure and mechanical properties of Ti $15 \mathrm{Mo} 6 \mathrm{Zr}$ based alloys were investigated by XRD, optical microscopy, and bending and compressive tests. The following conclusions can be drawn from this study:

- Optical micrographs showed that the Ti $15 \mathrm{Mo} 6 \mathrm{Zr}$ alloy mainly consisted of the $\left(\alpha^{\prime}+\beta\right)$ phase. After adding 1 wt. \%Cr, a small fraction of $\beta$ phase was detected. For Ti $15 \mathrm{Mo} 6 \mathrm{Zr} \times \mathrm{Cr}$ alloys, the texture of the entire alloy was transformed into a granular, equiaxed and completely retained $\beta$ phase. The average $\beta$ phase grain sizes decreased with increasing $\mathrm{Cr}$ content.

- The bending and compression strength of Ti15Mo6Zr was approximately the same as Ti15Mo6ZrxCr. Additionally, the Ti15Mo6Zr2Cr alloy had the lowest elastic modulus, which was lower $(86 \mathrm{GPa})$ than that of the Ti15Mo6Zr base alloy (99.6 GPa). 
- The Ti-15Mo-6Zr-2Cr alloy had lower bending and compression moduli (31 and $23 \mathrm{GPa}$, respectively) than the Ti-15Mo-6Zr-based alloys (40 and $36 \mathrm{GPa}$, respectively). Moreover, Ti$15 \mathrm{Mo}-6 \mathrm{Zr}-2 \mathrm{Cr}$ alloys exhibited higher bending and compression strength/modulus ratios, which were as large as 48.4 and 52.2 , respectively; these are higher than those of the Ti-15Mo-6Zr-based alloy (41.3 and 33.6, respectively). The $\beta$-phase Ti15Mo6Zr2Cr alloy exhibited the highest bending strength/modulus ratio.

- After a bending test, SEM images of the fractured surfaces showed that Ti $15 \mathrm{Mo} 6 \mathrm{Zr} 2 \mathrm{Cr}$ alloy exhibited mainly dimple ruptures, indicative of a typical ductile fracture. The fractured structures of Ti $15 \mathrm{Mo} 6 \mathrm{Zr} 1,2$, and $3 \mathrm{Cr}$ exhibited cleavage planes and a few dimple ruptures, pointing to a mixture of brittle and plastic mechanisms.

- The addition of $\mathrm{Cr}$ was effective at improving the mechanical properties of Ti $15 \mathrm{Mo} 6 \mathrm{Zr}$, especially the elastic moduli. In the current search for better implant materials, the low modulus and highest strength/modulus ratio of the $\beta$ phase of Ti $15 \mathrm{Mo} 6 \mathrm{Zr} 2 \mathrm{Cr}$ make it a promising candidate material for biomedical applications.

\section{ACKNOWLEDGEMENTS}

The authors thank the Ministry of Economy and competitiveness for financially supporting the research project MAT2014-53764-C3-1-R and the European Commission through the Erasmus Mundus scholarship program WELCOME. The European Commission via FEDER funds allowed for the purchase of equipment for research and Microscopy Service of the Polytechnic University of Valencia.

\section{REFERENCES}

[1] M. Geetha, A.K. Singh, R. Asokamani, A.K. Gogia "Ti based biomaterials, the ultimate choice for orthopaedic implants - A review" Progress in Materials Science 54 (2009) 397-425.

[2] Mansur Ahmed, DmytroG. Savvakin, Orest M.I vasishin, Elena V. Pereloma" The effect of ageing on microstructure and mechanical properties of powder $\mathrm{Ti}-5 \mathrm{Al}-5 \mathrm{Mo}-5 \mathrm{~V}-1 \mathrm{Cr}-1 \mathrm{Fe}$ alloy" Materials Science \& Engineering A605 (2014)89-97.

[3] Mitsuo Niinomi" Mechanical biocompatibilities of titanium alloys for biomedical applications" journal of the mechanical behavior of biomedical materials 1 (2008) $30-42$.

[4] M.P.Licausi, A.IgualMun, V.Amigo' Borra'"Influence of the fabrication process and fluoride content on the tribocorrosion behaviour of Ti6A14V biomedical alloy in artificial saliva" journal of the mechanical behavior of biomedical materials 20 (2013) $137-148$.

[5] Cvijovic -Alagic I, Gubeljak N, Rakin M, Cvijovic Z, Geric K. "Microstructural morphology effects on fracture resistance and crack tip strain distribution in Ti-6Al-4V alloy for orthopedic implants". Mater Des 53 (2014) 870 80.

[6] Chen YC, Chern Lin JH, Ju CP. "Effects of post-aging cooling condition on structure and tensile properties of aged Ti-7.5Mo alloy" Mater Des 54 (2014) 515-9.

[7] Lautenschlager EP, Monaghan P. "Titanium and titanium alloys as dental materials" Int Dent J 43 (1993) 24553.

[8] Long M, Rack HJ. “Titanium alloys in total joint replacement”a materials science perspective. Biomaterials 19 (1998) 1621-39.

[9] Long M, Rack HJ. Titanium alloys in total joint replacement a materials science perspective. Biomaterials 1998;19:1621-39.

[10] Niinomi M. Mechanical properties of biomedical titanium alloys. Mater Sci Eng, A 1998;243:231-6.

[11] Cheal E, Spector M, Hayes W. Role of loads and prosthesis material properties on the mechanics of the proximal femur after total hip arthroplasty. J Orthop Res 1992;10:405-22.

[12] Jinglian Fan, Mingyuan Lu, Huichao Cheng, Jiamin Tian, Boyun Huang "Effect of alloying elements Ti, Zr on the property and microstructure of molybdenum" Int. Journal of Refractory Metals \& Hard Materials 27 (2009) 7882 
[13] Ho WF, Wu SC, Hsu SK, Li YC, Hsu HC. "Effects of molybdenum content on the structure and mechanical properties of as-cast Ti-10Zr-based alloys for biomedical applications"Materials Science and Engineering C 32 (2012) 517-522.

[14] Ho WF. A.,"comparison of tensile properties and corrosion behavior of cast $\mathrm{Ti}-7.5 \mathrm{Mo}$ with c.p. Ti, Ti-15Mo and Ti-6Al-4V alloys" J Alloys Compd464 (2008) 580-3.

[15] Zhou YL, Luo DM. "Corrosion behavior of Ti-Mo alloys cold rolled and heat treated" J Alloys Compd509 (2011) 6267-72.

[16] Oliveira NTC, Guastaldi AC. "Electrochemical stability and corrosion resistance of Ti-Mo alloys for biomedical applications" Acta Biomater 5 (2009) 339-405.

[17] Chen Y, Xu L, Liu Z, Kong F, Chen Z. "Microstructures and properties of titanium alloys Ti-Mo for dental use"Trans Nonferrous Met Soc China 16 (2006) 824-8.

[18] Wen-Fu Ho, Shih-Ching Wu, Hsiao-Wei Wanga, Hsueh-Chuan Hsu, Effects of Cr addition on grindability of cast Ti-10Zr based alloys Materials Chemistry and Physics 121 (2010) 465-471.

[19] Donachie MJ. "Titanium: a technical guide" 2nd ed. Metals Park (Ohio): ASM International; 2000.

[20] Craig RG. "Restorative dental materials" 9th ed. St. Louis: CV Mosby; 1993.

[21] Hsu HC, Wu SC, Hsu SK, Lin TF, Ho WF. "Structure and mechanical properties of as-cast $\mathrm{Ti}-5 \mathrm{Nb}-\mathrm{xCr}$ alloys"Mater Des 51 (2013) 268-73.

[22] Hsueh-Chuan Hsu , Shih-Ching Wu, Shih-Kuang Hsu, Chien-Ting Li, Wen-Fu Ho" Effects of chromium addition on structure and mechanical properties of Ti-5Mo alloy" Materials and Design 65 (2015) 700-706.

[23] Syarif J, Rohmannudin TN, Omar MZ, Sajuri Z, Harjanto S. "Satability of the beta Phase in Ti-Mo-Cr Alloy Fabricated by Powder Metallurgy" J. Min. Metall. Sect B-Metall. 49 (3) (2013) 285-292.

[24] Syarif J, Kurniawan E, Rasani MR, Sajuri Z, Omar MZ, Harjanto S. " Influence of oxygen on microstructures of Ti-Mo-Cr alloy". Advanced Materials Research 896 (2014) 613-616.

[25] Pan Wang, Yan Feng ,Fengchao Liu, LihongWu, Shaokang Guan "Microstructure and mechanical properties of Ti-Zr-Cr biomedical alloys" Materials Science and Engineering C 51 (2015) 148-152.

[26] Wen-Fu Ho, Shih-Ching Wu, Hsiang-Hao Chang, Hsueh-Chuan Hsu" Structure and mechanical properties of Ti-5Cr based alloy with Mo addition" Materials Science and Engineering C 30 (2010) 904-909. 